\title{
Respiratory medicine and research at McGill University: A historical perspective
}

\author{
James G Martin MD DSc, Kevin Schwartzman MD MPH
}

JG Martin, K Schwartzman. Respiratory medicine and research at McGill University: A historical perspective. Can Respir J 2015;22(1):18-19.

The history of respiratory medicine and research at McGill University (Montreal, Quebec) is tightly linked with the growth of academic medicine within its teaching hospitals. Dr Jonathan Meakins, a McGill medical graduate, was recruited to the Royal Victoria Hospital in 1924; as McGill's first full-time clinical professor and Physician-inChief at the Royal Victoria Hospital. His focus on respiratory medicine led to the publication of his first book, Respiratory Function in Disease, in 1925. Meakins moved clinical laboratories from the Department of Pathology and placed them within the hospital. As such, he was responsible for the development of hospital-based research.

Dr Ronald Christie was recruited as a postdoctoral fellow by Meakins in the early 1930s. After his fellowship, he returned to Britain but came back to McGill from St Bartholomew's Hospital (London, United Kingdom) to become Chair of the Department of Medicine in 1955; he occupied the post for 10 years. He published extensively on the mechanical properties of the lung in common diseases such as emphysema and heart failure.

Dr David Bates was among Dr Christie's notable recruits; Bates in turn, recruited Drs Maurice McGregor, Margaret Becklake, William Thurlbeck, Joseph Milic-Emili, Nicholas Anthonisen, Charles Bryan and Peter Macklem. Bates published extensively in the area of respiratory physiology and, with Macklem and Christie, coauthored the book Respiratory Function in Disease, which integrated physiology into the analysis of disease.

Dr JA Peter Pare joined the attending staff of the Royal Victoria Hospital and the Royal Edward Laurentian Hospital in 1949. A consummate clinician and teacher, he worked closely with Dr Robert Fraser, the Chair of Radiology, to write the reference text Diagnosis of Diseases of the Chest. This was a sentinel contribution in its focus on radiographic findings as the foundation for a systematic approach to diagnosis, and the correlation of these findings with pathological and clinical observations.

Dr Margaret Becklake immigrated to Montreal from South Africa in 1957. Her research focused on occupational lung disease. She established the respiratory epidemiology research unit at McGill. She was renowned for her insistence on the importance of a clearly stated, relevant research question and for her clarity and insight.

Dr William Thurlbeck, another South African, had developed an interest in emphysema and chronic bronchitis and applied a structurefunction approach in collaboration with Peter Macklem and other respirologists. As chief of the Royal Victoria autopsy service, he used pathological specimens to develop a semiquantitative grading system of gross emphysema severity. He promoted the use of morphometry to quantify structural abnormalities.

Dr James Hogg studied the functional consequences of pathological processes for lung function during his $\mathrm{PhD}$ studies under the joint supervision of Drs Macklem and Thurlbeck. His contributions to understanding the structural basis for chronic obstructive pulmonary disease (COPD) are numerous, reflecting his transdisciplinary knowledge of respiratory pathology and physiology. He trained other outstanding investigators such as Peter Paré Jr, with whom he founded the Pulmonary Research Laboratory in St Paul's Hospital in Vancouver (British Columbia) in 1977.

A signal event in the evolution of respiratory research at McGill was the construction of the Meakins-Christie Laboratories in 1972. These laboratories were directed by Dr Peter Macklem, a trainee of Dr Becklake's. The research within the laboratory initially focused on respiratory mechanics, gas distribution within the lung and the contribution of airways of different sizes to the overall mechanical behaviour of the lungs. The effects of cigarette smoking on lung dysfunction, mechanisms of possible loss of lung elastic recoil in asthma and control of bronchomotor tone were all additional areas of active investigation. Dr Macklem pioneered the study of the physiological consequences of small airway pathology.

Dr Joseph Milic-Emili succeeded Dr Macklem as director of the Meakins-Christie Laboratories in 1979. Milic-Emili was renowned for his work on ventilation distribution and the assessment of pleural pressure. He led the development of convenient tools for the assessment of respiratory drive. He clarified the physiological basis for carbon dioxide retention in patients with COPD placed on high inspired oxygen concentrations.

Another area that captured many investigators' attention in the 1980s was the notion of respiratory failure as a consequence of respiratory muscle fatigue. Dr Charalambos ('Charis') Roussos made seminal contributions in this field. These studies triggered a long-lasting interest in respiratory muscle training, in rehabilitation, and in noninvasive mechanical ventilation for acute and chronic respiratory failure.

Dr Ludwig Engel obtained his $\mathrm{PhD}$ under the supervision of Peter Macklem and established himself in the area of ventilation distribution in health and in bronchoconstriction and the mechanics of breathing in asthma; he trained many investigators including one of the authors, Dr Jim Martin, who succeeded Milic-Emili as director of the Meakins Christie Laboratories from 1993 to 2008. Dr Martin developed small animal models of allergic asthma, and adopted a recruitment strategy that diversified the research programs at the Meakins Christie Laboratories.

Dr Manuel Cosio built on earlier work with Macklem and Hogg in his development of key structure-function studies of COPD. He was instrumental in recruiting a new generation of young investigators with interests in sleep medicine and neuromuscular diseases.

The 1970s and 1980s also witnessed the emergence of a topnotch respiratory division at the Montreal General Hospital, in large part reflecting the leadership of Dr Neil Colman, later a lead author of the revised Fraser and Paré textbook. At the Montreal General, areas of particular clinical strength and investigation included asthma, occupational and immunological lung diseases.

In 1989, the Meakins Christie Laboratories relocated to its current site on Rue St Urbain, adjacent to the Montreal Chest Institute. Dr 
Qutayba Hamid, on faculty at the Brompton Hospital, joined the Meakins-Christie Labs in 1994. In addition to an outstanding career in the area of the immunopathology of human asthma, he broadened the array of techniques routinely applied at the labs and has ably led the Meakins-Christie Labs from 2008 to the present.

The Meakins Christie Laboratories have had a remarkable track record that continues to this day. The basis for its enduring success is not immediately clear but it has almost certainly been linked to the balance of $\mathrm{MD}$ and $\mathrm{PhD}$ scientists that brought perspective and rigour. The diverse disciplines and research programs also facilitated adaptation to changing external research priorities.

The late 1990s and the early 21st century also saw the flourishing of the Respiratory Epidemiology Unit, under the leadership of Drs Pierre Ernst, Dick Menzies and Jean Bourbeau. It moved from McGill University to the Montreal Chest Institute in 2004. This paved the way for expanded clinical and translational research programs in COPD, tuberculosis, asthma, respiratory sleep disorders and other pulmonary diseases. The faculty now comprises respiratory clinicianresearchers and $\mathrm{PhD}$ scientists with expertise in epidemiological methods and biostatistics.

Respiratory physiology and medicine at McGill benefitted from a strong start through the influence of Meakins and Christie, and a tight linkage between clinical observation and physiological research. The subsequent recruitment of talented and creative faculty members with absolute dedication to academic medicine continued the legacy. No matter how significant the scientific contributions of the individuals themselves, their most important impact resulted from the training of a large cohort of other gifted physicians and graduate students. Some of these are further described in the accompanying full-length online article.

The full-length article can be viewed at the Journal's website at www.pulsus.com 


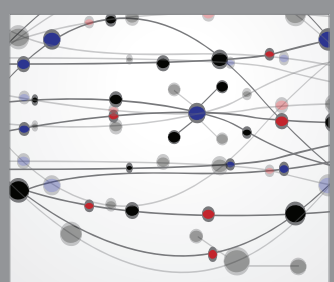

The Scientific World Journal
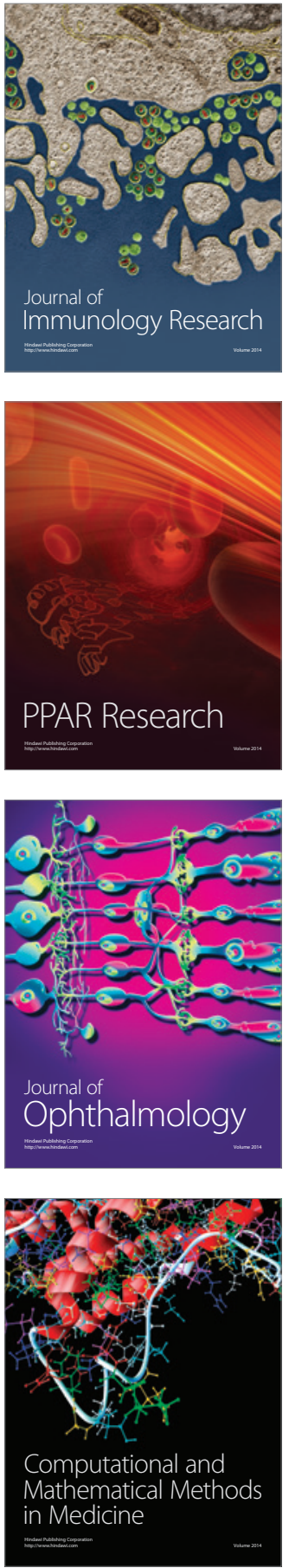

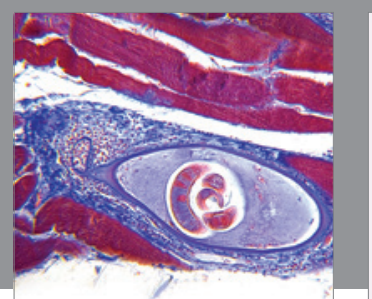

Gastroenterology Research and Practice

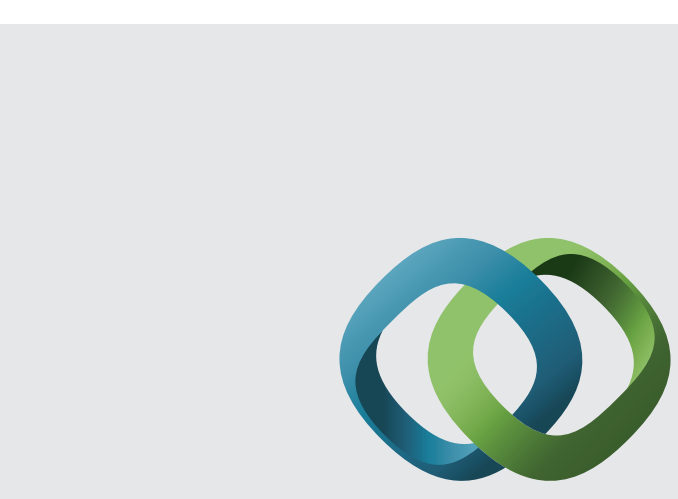

\section{Hindawi}

Submit your manuscripts at

http://www.hindawi.com
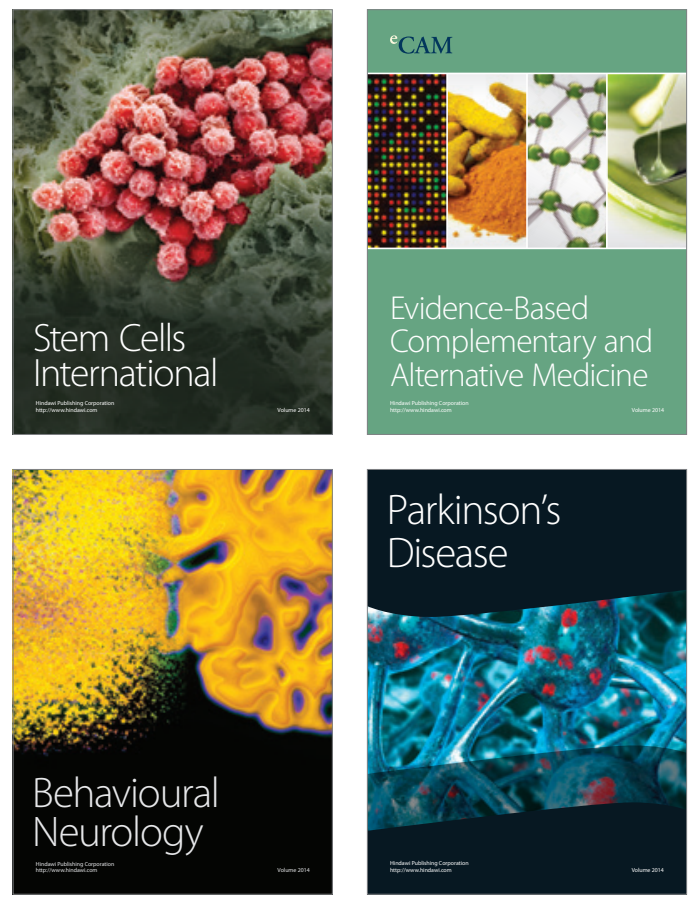
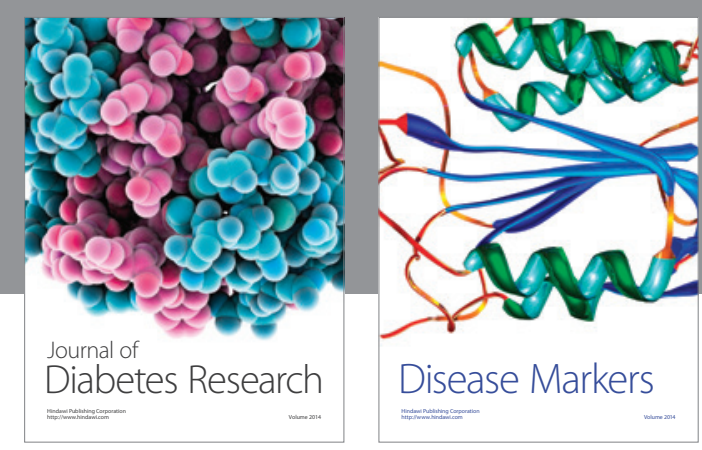

Disease Markers
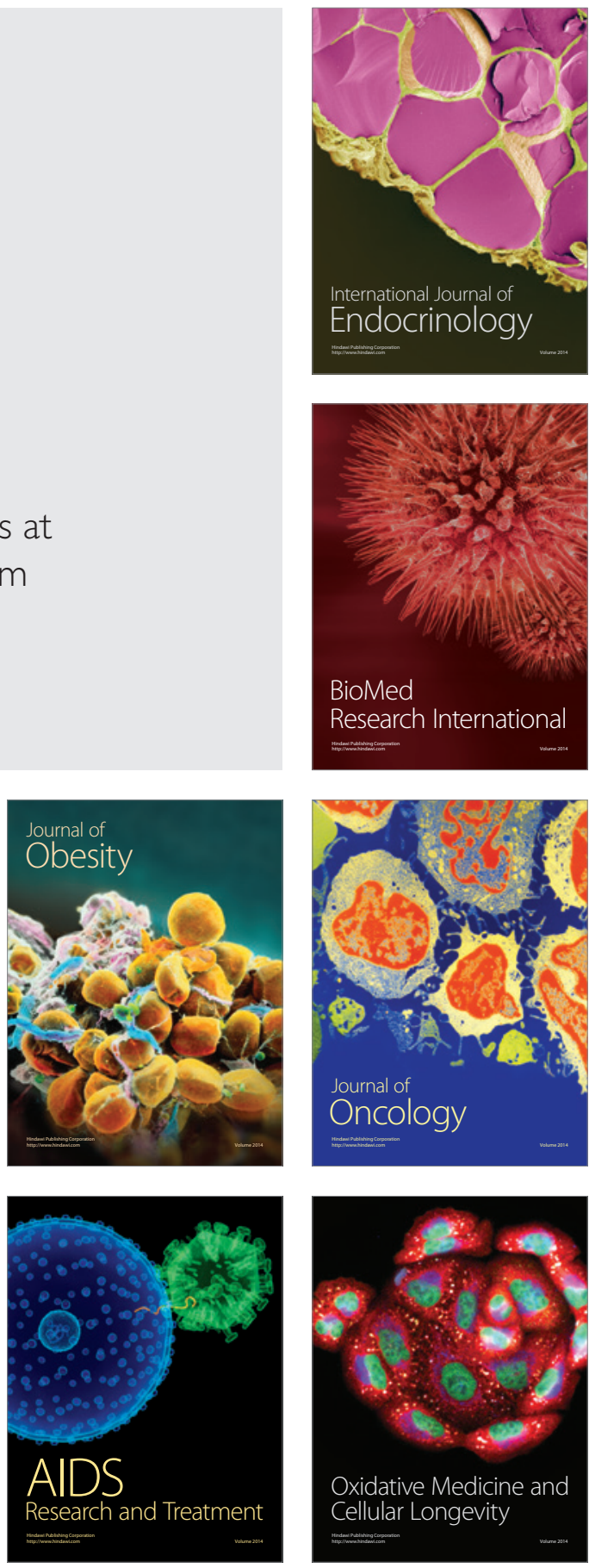